\title{
ENTRE A QUEIXA E A REFLEXÃO: A PROMOÇÃO DE MUDANÇAS NO DISCURSO DE UM GRUPO DE PROFESSORAS DE CIÊNCIAS DO ENSINO FUNDAMENTAL ${ }^{1}$
}

\author{
Between the complaint and the reflection: the promotion of changes in the speech \\ of a group of teachers of sciences of basic education
}

\author{
Marcelo Alves Barros ${ }^{2}$ \\ Sérgio de Mello Arruda ${ }^{3}$ \\ Carlos Eduardo Laburú ${ }^{4}$ \\ Michel Corci Batista ${ }^{5}$ \\ Andréia Itami da Silva ${ }^{6}$
}

Resumo: Este trabalho tem como objetivo compreender o processo de mudanças no discurso de um grupo de professoras de ciências do ensino fundamental que participaram de um curso de formação continuada. Ao analisar nossos dados foi possível identificar quatro etapas: a primeira, caracterizou-se por uma situação marcada por uma queixa generalizada; a segunda, pela necessidade de capacitação pelas professoras e a superação das deficiências de conteúdo decorrentes da precária formação no magistério; a terceira, por uma ênfase nos aspectos metodológicos das atividades de ensino e; a quarta, por um engajamento e uma postura mais reflexiva. Para interpretar nossos resultados utilizamos um esquema heurístico de orientação psicanalítica, denominado captura por discursos. Entre as principais conclusões podemos destacar que para que haja mudança do discurso da queixa para a reflexão o professor deve deslocar-se da castração imaginária para a castração simbólica, abandonando sua posição de impotência e resgatando sua autoridade perdida.

Palavras-chave: formação de professores; ensino de ciências; psicanálise e educação.

Abstract: This work has as objective to analyze the speeches of a group of teachers of basic education. When analyzing our data were possible to identify four stages: the first one, was characterized for a situation marked for a generalized complaint; second, for the necessity of qualification for the teachers and the overcoming of the

\footnotetext{
${ }^{1}$ Trabalho apresentado na forma de comunicação oral no $V$ Encontro Nacional de Pesquisa em Educação em Ciências, realizado no período de 28/11/05 a 03/12/05, Bauru/SP.

${ }^{2}$ Professor adjunto do Departamento de Física da Universidade Estadual de Maringá, Paraná, Brasil (e-mail:mbarros@dfi.uem.br).

${ }^{3}$ Professor associado do Departamento de Física da Universidade Estadual de Londrina, Paraná, Brasil(e-mail: renop@uel.br).

${ }^{4}$ Professor associado do Departamento de Física da Universidade Estadual de Londrina, Paraná, Brasil(e-mail:laburu@uel.br).

${ }^{5}$ Aluno de Iniciação Científica - PIC/UEM - do Departamento de Física da Universidade Estadual de Maringá, Paraná, Brasil (e-mail: corci@dfi.uem.br).

${ }^{6}$ Bolsista de Iniciação Cientifica - PIBIC/CNPq - do Departamento de Física da Universidade Estadual de Maringá, Paraná, Brasil (e-mail: itami@dfi.uem.br).
} 
decurrent deficiencies of content of the precarious formation in the teaching; third, for an emphasis in the methodological aspects of the activities of education e; fourth, for an enrollment and a new reflexive position. To interpret our results we use a heuristical project of psychoanalytical orientation, called capture for speeches. Among the main conclusions we can detach that so that has change of the speech of the complaint for the reflection the professor must dislocate itself from the imaginary castration for the symbolic castration, abandoning its position of impotence and rescuing its lost authority.

Keywords: teachers`' education; science education; psychoanalysis and education.

\section{Introdução}

As pesquisas sobre a formação de professores têm mostrado, de modo geral, que os professores entram nos programas de formação com crenças pessoais a respeito do ensino, com imagens do bom professor, imagens de si mesmos como professores e a memória de si próprios como alunos que geralmente permanecem inalteradas ao longo de tais programas e acompanham os professores durante suas práticas de ensino (Kagan, 1992).

Esses resultados são, até certo ponto, previsíveis e apontam para aspectos que devem ser enfrentados se a intenção é a de provocar reflexões no professor, sejam elas de natureza curricular, sejam na direção da condução e sustentação do processo de aprendizagem e do controle da sala de aula.

Outras dificuldades de diferentes naturezas também devem ser levadas em consideração como, por exemplo, o fato de que o professor apresenta, de modo geral, uma formação acadêmica precária que acaba por fragilizar sua competência didática, recebe um salário incompatível com a sua responsabilidade e é um profissional pouco valorizado pela sociedade. Além disso, em muitas escolas as equipes técnicas (direção, coordenação e supervisão pedagógicas) mal conseguem sustentar o trabalho do professor em suas salas de aula.

Diante dessa conjuntura é praticamente impossível que o professor não se dirija a seus alunos a partir de um discurso reduzido à impotência, até porque tem consciência de suas fragilidades. Muitas pesquisas vêm apontando há algum tempo que é somente a partir de um certo nível de competência que o professor leciona sem posicionar-se em uma atitude defensiva, podendo, então, trabalhar de acordo com uma boa performance (Pacca \& Villani, 2000). E, sem dúvida, essa performance exige que o professor, como propõe Perrenoud (1999-a), crie, desenvolva e pratique diferentes habilidades e competências que lhe permitam agir eficazmente em determinados tipos de situação, apoiado em conhecimentos, mas sem limitar-se a eles. O desenvolvimento 
de tais capacidades parece requerer do professor, não somente um processo reflexivo e crítico sobre suas ações (Schön, 1992; Nóvoa, 1992; Tardif, 2000), mas ao mesmo tempo a recusa da impotência que lhe foi atribuída. Para que isso ocorra parece-nos fundamental que o professor possa se reconhecer enquanto um profissional, particularmente no sentido de que se apóia em conhecimentos especializados e formalizados e que possui a competência de utilizá-los em sua prática.

Neste trabalho nosso objetivo consiste em compreender o processo de mudanças no discurso de um grupo de professoras de ciências do ensino fundamental introduzidas por meio de um curso de formação continuada e interpretá-las a partir de um esquema heurístico que aponta para aspectos relacionados às escolhas subjetivas do sujeito. Nossa premissa de trabalho é de que o professor ocupa uma posição subjetiva marcada por uma satisfação inconsciente que o amarra num determinado tipo de discurso que estrutura suas falas e ações, podendo favorecer ou dificultar o ensino e a aprendizagem de sua disciplina.

\section{Metodologia de Pesquisa}

Os dados para realização de nossa pesquisa foram coletados no $2^{\circ}$ semestre de 2003, no Curso de Extensão: "Ciências no Ensino Fundamental: O Conhecimento Físico". O curso realizou-se no período de 02/09/03 a 09/12/03, envolvendo 10 professoras de $1^{\mathrm{a}}$ a $4^{\mathrm{a}}$ séries da rede municipal de ensino da cidade de Maringá/PR. No total foram realizados 15 encontros, com carga horária semanal de 4 horas.

Todos os encontros foram gravados em vídeo e, posteriormente, transcritos na íntegra. Nosso recorte de análise consistiu em buscar selecionar aqueles momentos marcantes que evidenciassem as mudanças dos discursos presentes nas falas das professoras ao longo do curso. Entre algumas perguntas que serviram de subsídios para a escolha daqueles episódios de ensino podemos citar: De que posição estas professoras estavam falando? Qual a demanda presente em seus discursos? Qual a satisfação inconsciente que amarrava estas professoras numa determinada busca?

Também procuramos identificar quais seriam os elementos presentes nos discursos de cada uma das professoras que estivessem em ressonância com o restante do discurso do grupo. Do ponto de vista do grupo havia um discurso que era produzido e compartilhado pelas professoras e marcava a direção das mudanças ocorridas ao longo dos encontros sucessivos. Este discurso do grupo constitui-se em 
outro aspecto importante para a escolha dos episódios de ensino significativos das mudanças observadas nos tipos de discursos das professoras.

Dos relatos das professoras e das discussões que ocorreram ao longo dos encontros emergiram elementos que constituíram os saberes mobilizados por elas, sejam aqueles implícitos, sejam os conhecimentos formalizados e consolidados em que cada uma se apóia em seu trabalho.

Nossa proposta de ensino se pautou numa metodologia de intervenção que priorizou fundamentalmente a realização de atividades múltiplas e diversas, tais como discussões, leituras, dramatizações, análises de aulas, planejamentos, docência, avaliações e o desenvolvimento de um trabalho em grupo que criasse condições efetivas para a instauração de um clima de parceria entre as professoras e entre estas e o docente responsável. Procuramos criar condições de as professoras se engajarem numa proposta de tentar compreender os vários elementos envolvidos nas situações de ensino, bem como as diversas possibilidades de incorporação dos resultados de pesquisa em seu trabalho.

\section{Referencial Teórico}

Para análise e interpretação dos nossos dados utilizamos conceitos extraídos da psicanálise de orientação lacaniana. Segundo Lacan, o sujeito passa a se constituir a partir do que ele denominou de Outro (lê-se: grande outro), uma ordem anterior e exterior ao sujeito, um discurso universal estruturado como uma linguagem, que sanciona tudo o que tentamos comunicar através da nossa fala. O Outro também é o que organiza a nossa vida psíquica, pois é a partir do Outro que falamos e desejamos.

O Outro poderia ser representado como a "coleção de todas as palavras e expressões de uma língua” (Fink, 1998), a qual nos foi conferida por séculos de tradição. Esse Outro também pode ser entendido como a cultura, definida como um fluxo discursivo, ou seja, "tudo o que foi se articulando discursivamente, oralmente ou por escrito, no quadro dessa cultura" (Calligaris apud Kupfer, 1999). Nesse sentido, o Outro seria constituído como uma superposição de discursos, já que socialmente estamos inseridos em grupos, instituições, ideologias e culturas diversas, cada uma delas apresentando características próprias e um particular dialeto. Muitas vezes essas culturas giram em torno de uma ou mais idéias ou valores, implícitos ou explicitados, certos conceitos articuladores, aos quais são denominados em psicanálise de 
significantes. Nesse sentido, o Outro pode ser entendido como aquele que dá ao sujeito uma referência, através dos significantes.

O importante é ressaltar que uma vez capturado por um discurso o sujeito vai seguir a trilha dos significantes daquele campo. Vai desempenhar certos papéis que são atribuídos por aquele discurso, sendo por ele definido e por ele demandado. Quando capturado, mais do que falar ou pensar por "si mesmo", o individuo é falado e pensado pelo Outro. Ele está alienado na linguagem, no discurso desse Outro. Até mesmo o desejo do sujeito é estruturado a partir desse Outro, tal que também poderíamos dizer que o desejo do sujeito é o desejo do Outro.

O Outro, entretanto, não existe como uma entidade abstrata, mas se materializa na nossa vida através dos outros, dos semelhantes com quem convivemos. Inicialmente nossos pais, depois os nossos professores, os nossos mestres ou qualquer autoridade, cada um desses sujeitos assume periodicamente a função de grande Outro, de modo que o discurso e o desejo do Outro flui para nós através desses indivíduos.

A partir desses conceitos Arruda \& Villani (2001), estabeleceram a hipótese de que as falas e as ações dos professores poderiam ser explicadas como o resultado de capturas por diferentes tipos de discurso, os quais estruturam suas falas, seus desejos e seus diferentes tipos de satisfação inconsciente. Segundo os autores teríamos a possibilidade de captura por sete diferentes discursos:

- Discurso do Consumo: introduz demandas que nada têm a ver com a procura de conhecimento científico. Os interesses do professor não se complementam com os da escola, mas ele permanece na instituição na medida em que consegue evitar desencontros mais graves com as exigências do discurso escolar dominante. $\mathrm{O}$ trabalho do professor é visto como uma mera complementação salarial e há ausência de compromisso com a profissão.

- Discurso da Burocracia: demanda o cumprimento dos ritos burocráticos que garantem as aparências e leva o sujeito a não se posicionar frente aos problemas reais da escola ou de outras instituições. Importa mais cumprir as regras do que ensinar os alunos. O professor não tem compromisso e não se implica realmente com mudanças, sempre encontrando dificuldades e poucas condições para a realização de seu trabalho. Tampouco há condições para que o professor reflita sobre o que faz e todos estão convencidos de que o que se faz fora da rotina gera problemas e está condenado ao fracasso. 
- Discurso do Conhecimento Científico: privilegia o conhecimento científico, os manuais e os livros-texto. O papel do professor é tornar-se a fonte do conhecimento e transmiti-los aos alunos, identificando-se com a figura do mestretodo, ou seja, aquele que detém o conhecimento a ser ensinado. Por um lado, há uma insatisfação dos professores com a falta de domínio do conteúdo, com a metodologia tradicional e com o desinteresse dos alunos e, por outro, uma preocupação com sua formação para melhorar esses aspectos.

- Discurso do Conhecimento Metodológico: promete resolver o problema da falta de motivação dos alunos para as atividades escolares e para o estudo em particular. Mais especificamente, sinaliza a possibilidade de metodologias, estratégias e inovações tecnológicas que conseguiriam dar conta de um domínio satisfatório da sala de aula. O professor parece procurar um método a prova de suas próprias falhas, que funcione pelas suas qualidades intrínsecas, uma "nova maneira de ensinar". Basta achar os elementos adequados e o ensino torna-se uma tarefa fácil e agradável.

- Discurso do Conhecimento Reflexivo: seria uma fase posterior do discurso do conhecimento, que corresponderia à adesão ao conhecimento teórico e prático sobre a aprendizagem em ciências, que enfatiza a necessidade de participação ativa do aluno em sua aprendizagem. Focaliza a atividade reflexiva do professor, para que ele possa acompanhar a evolução da aprendizagem de seus alunos. O mote principal desse discurso é uma construção pessoal do conhecimento, vislumbrando a possibilidade de uma certa originalidade do aprendiz.

- Discurso da Pesquisa Orientada: sua ênfase é a crítica ao conhecimento estabelecido e a produção de novo conhecimento. Surge sob orientação de um pesquisador mais experiente, ou seja, num contexto de prestar conta para alguém e/ou para um determinado referencial que não está sujeito à contestação. Aponta para a produção de um novo conhecimento pelo professor e, portanto, para o encontro com possíveis conflitos, angústias e dúvidas.

- Discurso da Pesquisa Autônoma: é o discurso que focaliza a resolução de problemas originais, a partir de alguma tradição de pesquisa. É o discurso da criação, da elaboração de algo original, sem a necessidade de prestar conta para uma instância superior. O professor capturado por esse discurso torna suas próprias aulas e sua prática de ensino objetos de pesquisa. O ponto importante é que sua busca sem fim marca implicitamente seus alunos. 
Segundo os autores, quando capturado por um discurso, o sujeito tende a desenvolver ações repetitivas, pois o aprisionamento num determinado discurso envolve uma satisfação inconsciente e, embora a captura por um determinado discurso possa expressar aspectos conscientes, o que interessa está diretamente relacionado aos aspectos inconscientes da escolha do sujeito. Cada discurso implica num determinado nível de envolvimento e visão da docência, uma vez que cada discurso estrutura de uma maneira diferente o desejo de saber dos professores e sua relação com a profissão. Isso explicaria a maior ou menor disponibilidade dos professores em se envolverem e aderirem às mudanças.

\section{Análise e Interpretação dos Dados}

Ao analisar nossos dados foi possível identificar quatro etapas bastante distintas nas falas das professoras.

$\mathrm{Na}$ primeira etapa, nossos dados permitiram detectar uma situação de impasse e de repetição marcada por um conjunto de queixas e atitudes por parte das professoras. As professoras revelaram sua impotência e fracasso diante dos alunos, admitindo que nada poderia ser feito: "Eu tinha uma criança na $4^{a}$ série que não lia uma palavra, e ele podia ficar 10 anos na $4^{a}$ série que ele não ia ler”. As professoras também recusaram o papel de responsabilidade diante do despreparo dos alunos, transferindo-o para a família e reconhecendo que o seu trabalho era solitário e condenado ao fracasso: "Escola pública não tem apoio de pai, é um ou outro que ajuda seu filho... se os pais cobram mais, se os pais exigem mais e dão esse apoio para o filho, ele tem a capacidade de acompanhar melhor a aula, agora se ele é um largado e ninguém nem olha o seu caderno, não tem jeito, e aí ele vai mostrar para quem? Não tem, e aí ele tá ali porque é obrigado, ele não tem interesse, não tem um estímulo maior”. Em nossa interpretação o que está subjacente a essas queixas das professoras é a tentativa de sempre buscar de que ou de quem se culpar. Assim, tanto numa situação como em outra as professoras nunca viam o problema como sendo seus. Suas dificuldades provinham das falhas dos outros. O problema estava sempre no outro, os outros eram os culpados ${ }^{7}$. No início do curso as professoras evitaram o risco de se expor e o discurso dominante foi o da burocracia.

\footnotetext{
${ }^{7}$ Para uma descrição mais detalhada dos dados obtidos na primeira etapa ver Barros et. al (2004).
} 
A segunda etapa marcou a saída das professoras da inércia inicial marcada pelo discurso da burocracia e a captura pelo discurso do conhecimento científico, caracterizado pelo reconhecimento das deficiências de conteúdo decorrentes da precária formação no magistério: "ele (o aluno) gosta muito de ciências, então ele falou assim, que ele se aprofunda muito na ciência por isso que ele está sabendo falar estas coisas. Nem eu sabia explicar a propulsão dele. O que é propulsão (pergunta para o docente)?”. Outro aspecto importante diz respeito ao reconhecimento pelas professoras da necessidade de capacitação permanente: "Eu acho que a gente tem que ser bem realista com as coisas, porque a professora também não sabe (...) a gente não sabe tudo e nem somos obrigados a saber”. Ou ainda: “(...) no magistério a gente vê pouca ciência, ciências a gente vê muito pouco. (...) o meu direcionamento é para alfabetização, sempre com a $1^{a}$ série. Então para mim foi muito interessante e muita coisa eu descobri aqui. Pra gente foi uma surpresa". Ao falar sobre suas dificuldades as professoras foram capazes de tomar consciência dos problemas relacionados ao conteúdo: “(...) Aqui nós fizemos papel de aluno porque realmente nós não tivemos. Eu, por exemplo, fiz escola normal numa cidadezinha pequenina, era três anos, e que era só de $1^{a}$ a $4^{a}$ séries, você era preparado para dar aula de $1^{a}$ a $4^{a}$. Não tinha física, não tinha química, não tinha nada dessas coisas. Então a gente não viu mesmo”.

A terceira etapa foi marcada predominantemente por uma ênfase mais acentuada na forma de propor as atividades de ensino e o discurso dominante foi o do conhecimento metodológico. Parece-nos que após as professoras darem-se conta das deficiências de conteúdos ligados à formação de magistério, elas passaram a se preocupar mais com a forma de promover a aprendizagem dos alunos do que unicamente com a transmissão de conteúdos científicos. No entanto, devemos chamar atenção para o fato de que essas professoras passaram a se apropriar da metodologia de ensino como se tratasse de um método milagroso para os diversos dilemas enfrentados por elas em seu dia-a-dia: "Nós chegamos a conclusão que se a gente seguir aqueles passos que você deu e a gente anotou, é muito fácil fazer experiência, não dá trabalho". Ou também: "Eu acho que se a gente busca uma motivação para a criança, não tem coisa melhor, eu não vi até hoje forma de encaminhar o conteúdo assim tão bem bolado como está sendo estas atividades". Também podemos destacar a ênfase na metodologia e nas diferentes estratégias de ensino: “Começar a mostrar para o professor que tem maneiras e maneiras da gente encaminhar um conteúdo, uma atividade”. Também destacamos a preocupação das professoras em promover a 
motivação dos alunos como algo diretamente relacionado ao jeito de dar aulas: “(...) achei que foi muito valioso, porque acharam uma aula diferente, ficaram muito motivados, todos empolgados".

A quarta etapa foi marcada por uma mudança no discurso das professoras que, após superarem os problemas com o conteúdo e a metodologia de ensino, foram capturadas pelo discurso do conhecimento reflexivo: "Está acontecendo uma coisa assim comigo que eи estou tendo que me policiar na hora de aplicar essas atividades, porque está na gente, na nossa formação aquela história de querer dar a solução". Ou também: "Aí eu fui puxando por eles, para eles poderem chegar...”. Neste discurso as professoras expressam uma preocupação maior por uma produção mais autônoma pelos alunos: “(...) a gente quer que eles escrevam, que eles não fiquem inibidos. Eu achei que eles se desenvolveram bastante (...) eu não sabia que eles estavam tão adiantados na escrita daquele jeito para escrever idéias (...) é isso que a gente quer que eles escrevam sem estar se preocupando muito com erros de português, porque se eles se preocupam com isso, vão ter um bloqueio para escrever”, e pela valorização das suas idéias: “(...) aí ele (o aluno) já começou a explicar sobre isso (o eclipse), já explicou para a sala inteira, aí eu já chamei a atenção, olha gente, dá uma olhada no que ele está explicando, aí a gente já passou para a sala inteira. Eu fiquei admirada, me surpreendeu”.

Também podemos destacar as criticas as aulas tradicionais às quais estavam tão habituadas: "Eu mesma já falei várias vezes que eu dou a experiência para os meus alunos toda vida, eu gosto dessas coisas, eu adora trabalhar brincando com eles, mas eu primeiro eu passava o texto, daí eu ia comprovar. Agora não, hoje eu aprendi uma coisa, saio lá fora, levo né, dou para eles brincarem, para depois eu conduzir através deles a minha aula. Modificou muita coisa”. Ou ainda: “(...) se fosse daquela outra forma (tradicional) a gente ia passar um texto para eles, ia dar a explicação do texto para a criança, depois a gente ia lá fora só confirmar. Essa é a diferença. Eles mesmos fizeram e eles mesmos produziram, eles mesmos tiraram as conclusões, né? Eu achei assim, eu fiquei encantada, sabe?”.

Essas quatro etapas apontam para a passagem do discurso das professoras de uma posição marcada inicialmente pela rejeição e queixa para uma situação na qual passaram a se implicar nas questões de ensino, aceitando suas limitações de conteúdo e procurando se apropriar do conhecimento científico. Em seguida, apareceu um outro tipo de discurso que apontou para a questão da metodologia de ensino como ponto- 
chave e a solução para os problemas de ensino. Finalmente, um último discurso mais reflexivo que valorizou mais a iniciativa e a produção pessoal dos alunos, com a responsabilidade crescente das professoras.

\section{Comentários Finais}

Para a psicanálise lacaniana a linguagem é condição do inconsciente e, portanto, da condição da construção das instituições humanas, entre elas a escola. Disso podemos empreender que, uma vez que a escola está sujeita às leis de funcionamento da linguagem, também podemos ler os discursos que ali se desenrolam da mesma maneira que se lê o discurso de um sujeito em análise.

Quando o sujeito está capturado pelo discurso da burocracia podemos dizer que ele fala de uma posição marcada pelo lugar da instituição, ou em outras palavras, ele está capturado pelo discurso da instituição. Segundo Kupfer (2000), o discurso institucional tende a produzir repetições, mesmice, na tentativa de preservar o igual e garantir sua permanência. De acordo com a autora, quando houver apenas repetições, quando houver apenas discursos cristalizados, os sujeitos não poderão manifestar-se. Nesse caso, o resultado poderá ser a impossibilidade de criação de novos discursos, mais flexíveis e sujeitos às mudanças. O professor capturado por esse discurso tende a fixar os alunos em estereotipias, em modelos que lhes são pré-fixados, daí resulta o fracasso escolar.

De modo contrário, quando há circulação de discursos, as pessoas podem se implicar em seu fazer, podem participar dele ativamente, podem se responsabilizar por aquilo que fazem ou dizem. Mudam ativamente os discursos, assim como são por eles mudadas, de modo permanente.

Também devemos ressaltar que o mundo contemporâneo está marcado pela fragmentação da sociedade e do sujeito, no qual prevalece o registro do imaginário com os objetos, adquirindo um sentido absoluto, desligado do passado. Do domínio desse imaginário o professor encontra-se castrado imaginariamente. Entendemos por castração imaginária a castração como reveladora de impotência. Por outro lado, chamamos de castração simbólica aquela que é estruturante do sujeito, que causa o seu desejo e o empurra em direção ao trabalho (Kupfer, 1999).

Como promover a ultrapassagem da castração imaginária para a simbólica? 
Para ocorrer essa passagem da castração imaginária para a castração simbólica é necessário resgatar a autoridade perdida pelos professores. Para que haja circulação do discurso da burocracia para a reflexão o professor deve deslocar-se da castração imaginária para a castração simbólica, abandonando sua posição de mestre da impotência e assumindo uma posição de mestre não-todo.

A definição de mestre não-todo surge em contraposição à posição de mestre todo, que significa aquele que sustenta um discurso no qual o sujeito da castração não aparece. Em seu lugar surge um agente que supõe dominar a linguagem que desdobra diante de seu ouvinte. Imagina que seu discurso não tem falhas e acredita ilusoriamente ser o mestre de tudo, dono do saber.

Uma condição para que o professor de hoje, despossuído de traços imaginários que dão sustentação ao ofício de sua profissão docente, resgate sua autoridade perdida está na recusa da impotência que lhe foi imputada. Outra condição é ele "fazer de conta" que na verdade é um mestre todo, ou seja, que fala de uma posição de quem é detentor do saber e do poder de ensinar, sem, contudo, acreditar realmente nisso. Segundo Kupfer (op. cit.), a tentativa de recuperar a dignidade da figura do professor deve ser exercida por um mestre que se sabe irremediavelmente não-todo, ou seja, não por causa da castração imaginária, mas por efeito da castração simbólica.

Assim, o professor poderá responder a seus alunos e à sociedade diante da sua castração simbólica e não imaginária. Um mestre não-todo que finge ser mestre todo, mas que leva em consideração sua castração simbólica. Desse modo, o professor poderá tornar-se um sujeito desejante, mas nem por isso despossuído de autoridade. Dessa posição surge uma nova autoridade sustentada por um mestre que não mais se apóia em conhecimentos distantes e absolutos, que precisa estar bem mais próximo de sues alunos e que não se deixa levar pelo sentimento de fracasso e impotência.

Também ressaltamos a função exercida pela demanda externa na determinação de uma ação. A pressão de uma exigência institucional se coloca, de fato, como um fator indispensável, na maioria dos casos para a realização de certas tarefas. A explicação é que a elaboração de um saber não é um processo que ocorre espontaneamente, mas exige esforço. Em conseqüência, para se despertar o que poderia ser chamado de desejo de saber talvez se tenha de passar, num primeiro momento, pela demanda externa. O contato constante e cotidiano com uma demanda 
intelectual vinda da instituição pode inserir o sujeito em um outro circuito de satisfação.

A partir da localização dos significantes e os discursos nos quais um professor está capturado, como fazer para que ele mude de discurso? A saída de um circuito inercial se dá quando o sujeito experimenta um novo discurso, inicialmente via uma demanda externa. Nesse momento intervém o sujeito, que pode romper com a repetição e entrar numa nova fase. Mas é preciso que a nova posição seja sustentada por alguém através de uma relação transferencial pedagógica, entendida como a instauração de uma confiança mútua.

Por outro lado, a passagem de um discurso a outro ocorre de forma gradual, ou seja, para se deixar capturar por outro discurso é preciso que esse novo discurso esteja localizado em uma zona de saber proximal (Arruda \& Villani, 2001). Trata-se de uma expressão inspirada na idéia da zona de desenvolvimento proximal de Vygotsky, segundo a qual o professor precisaria criar zonas de desenvolvimento proximal, pois se o que está se querendo ensinar estiver muito distante do que o aluno consegue fazer por si só, ele não aprenderá, mesmo com a ajuda do professor. É preciso levar em consideração que o saber elaborado pelo aluno é um conhecimento (isto é, conjunto de idéias, conceitos etc.) amarrado a alguma satisfação (Pacca \& Villani, 2000). Para que alguém aprenda de maneira marcante alguma coisa, é preciso que esse novo conhecimento traga alguma satisfação para o sujeito, ou seja, ser sustentado por algum tipo de discurso. Talvez mais do que ter algum significado, o novo conhecimento, para se tornar saber próprio do indivíduo, tem de estar ancorado a um novo significante e com ele a uma nova satisfação, que é o que faz o sujeito investir na sua compreensão. Nesse sentido, a mudança de um discurso a outro se dá de forma gradual, às vezes passando por um discurso intermediário, por algum saber proximal, que pode ter sido construído previamente pelo próprio sujeito ou estar sendo evocado e ampliado pelo professor na sua intervenção. Nesse sentido, o professor deve estar atento para saber graduar seu discurso de modo que ele possa fazer sentido para os alunos.

Em nosso trabalho identificamos quatro diferentes tipos de discursos de professores de ciências que participaram de um curso de formação continuada. No primeiro tipo de discurso predominou um discurso burocrático que engessava a prática didática e a tornava inquestionável por um tempo bastante longo. As professoras parecem ter aderido à conclusão de que com alunos daquele tipo não dava para esperar 
muito mais. As professoras estavam, em boa parte, preocupadas inconscientemente em prestar conta para a instituição, sem se questionar se isso era a melhor forma de ensinar.

Devemos destacar que a iniciativa para romper com esse discurso foi através de uma professora que, ao aplicar as atividades de ensino em suas aulas e relatar entusiasmada para as demais professoras a sua experiência de êxito, introduziu uma nova dinâmica de trabalho que contribuiu para aumentar a segurança das demais professoras para aplicar as atividades com seus alunos.

Outro aspecto refere-se ao papel do grupo na sustentação do processo de mudança que cada professora vivenciou no enfrentamento de suas crenças pessoais na análise de suas práticas, após o término das correspondentes experiências de ensino. Ele foi fundamental para sustentar as mudanças produzidas ao longo do curso. O grupo atuou de maneira positiva, procurando entender e não criticar, levantando hipóteses no lugar de defendê-las, o que deixou cada professora à vontade para explicitar suas satisfações pessoais. Por isso, podemos supor que a presença de um grupo de reflexão, capaz de conduzir esse tipo de questionamento em seus participantes, seja um auxílio muito importante para a melhoria da prática docente.

No que diz respeito à utilização de um referencial psicanalítico para interpretar os discursos das professoras podemos considerar que a utilização da psicanálise ao tentar levantar questões sobre as satisfações inconscientes das professoras pode auxiliar de maneira decisiva para focalizar o núcleo dos impasses, causas de resistências às mudanças e as possibilidades de mudança significativa (Villani et al., 2004). Uma outra consideração nos leva a perguntar se a reflexão e análise dos casos podem influenciar a postura implícita de cada professora em sala de aula. Sem dúvida não se tem nenhuma garantia de que a análise de casos, mesmo que se refiram ao próprio professor, tenha efeitos nas relações inconscientes que ele estabelecerá na sucessiva atuação docente. Porém, se ele conseguir efetivamente se deixar atravessar por questões do tipo: "O que queria naquela situação?". "Que tipo de satisfação me amarrava?", sem dúvida resultará num certo afastamento daquela satisfação e numa maior chance de atuar de maneira diferente nas futuras situações. 


\section{Referências Bibliográficas}

ARRUDA, S. M. e VILLANI, A. Formação em serviço de professores de ciências no Brasil: contribuições da psicanálise. In: III Encontro Nacional de Pesquisa em Ensino de Ciências, CD-ROM, Atibaia, SP, 2001.

BARROS, M. A., ARRUDA, S. M., BATISTA, M. C. e SILVA, A. I. O lugar da queixa na constituição da subjetividade de um grupo de professoras de ciências de $1^{\text {a }}$ a $4^{\text {a }}$ séries do ensino fundamental. In: IX Encontro de Pesquisa em Ensino de Física, CD-ROM, Jaboticatubas, MG, 2004.

FINK, B. O sujeito lacaniano. Jorge Zahar Editor, Rio de Janeiro, 1998.

KAGAN, D. M. Professional Grouth among preservice and beginning teachers. Review of Educational Research, vol. 62, n 2, p. 129-169, 1992.

KUPFER, M.C. Por uma vara de vidoeiro simbólica. In: AQUINO, J.G. Autoridade e Autonomia na Escola. Alternativas teóricas e práticas. Summus Editorial, São Paulo, SP, 1999.

KUPFER, M.C. Educação para o futuro. Psicanálise e Educação. Editora Escuta, São Paulo, SP, 2000.

NÓVOA, A. Formação de professores e profissão docente. In: Os professores e a sua formação. Nóvoa (org.), Lisboa, Dom Quixote, 1992.

PACCA, J.L.A. \& VILLANI, A. La competencia dialógica del profesor de ciencias en Brasil. Enseñanza de las Ciencias. 18 (1): 95-104, 2000.

PERRENOUD, P. Construir as competências desde a escola. Porto Alegre, Artmed Editora, 1999a.

SCHÖN, D. A. Formar professores como profissionais reflexivos. In: Os professores e a sua formação, Nóvoa (org.), Lisboa, Dom Quixote, 1992.

TARDIF, M. Saberes profissionais dos professores e conhecimentos universitários: elementos para uma epistemologia da prática profissional dos professores e suas conseqüências em relação à formação para o magistério. Revista Brasileira de Educação (ANPED). n 13, 2000.

VILlANI, A., BARROS, M. A. e ARRUDA, S. M. Impasses na Sala de Aula de Ciências: a Psicanálise Pode Auxiliar? II Encuentro Iberoamericano sobre Investigación Básica en Educación en Ciencias, 21 a 24 de setembro, Burgos/Espanha, 2004. 